\title{
PENERAPAN METODE BACKPROPAGATION UNTUK MEMPREDIKSI JUMLAH KUNJUNGAN WISATAWAN BERDASARKAN TINGKAT HUNIAN HOTEL
}

\author{
Romy Aulia \\ Sistem Informasi, STMIK Royal Kisaran \\ romysinggalang@gmail.com
}

\begin{abstract}
Tourism is one of the most important factors for the revenue of an area. To attract the interest of tourists takes some supporting factors, one of which is the hotel or the guesthouse. In the process of prediction of tourists visit, required data the number of tourists staying in order to predict for the next time. The prediction method used in this system is a method of Backpropagation Neural Network based on time series data forecasting component variansi random or random process beginning with autocorrelation for determination of input variables. Method of Backpropagation itself is known quite well used in the forecasting of time series data. The result of the method of Backpropagation is a number of predictions that tourists visit can be a reference for related officials in taking decisions for the period ahead.
\end{abstract}

Keywords: neural network, backpropagation, forecasting, tourist

\begin{abstract}
Abstrak: Pariwisata adalah salah satu faktor paling penting untuk pendapatan suatu daerah. Untuk menarik minat wisatawan dibutuhkan beberapa faktor pendukung, salah satunya adalah hotel atau wisma. Dalam proses prediksi kunjungan wisatawan, diperlukan data jumlah wisatawan yang tinggal untuk memprediksi untuk waktu berikutnya. Metode prediksi yang digunakan dalam sistem ini adalah metode Backpropagation Neural Network berdasarkan time series data forecasting komponen variansi acak atau proses acak yang dimulai dengan autokorelasi untuk penentuan variabel input. Metode Backpropagation sendiri diketahui cukup baik digunakan dalam peramalan data deret waktu. Hasil dari metode Backpropagation adalah sejumlah prediksi yang kunjungan wisatawan dapat menjadi referensi bagi pejabat terkait dalam mengambil keputusan untuk periode mendatang.
\end{abstract}

Keyword: syaraf tiruan, backpropagation, peramalan, pariwisata

\section{PENDAHULUAN}

Sektor pariwisata merupakan sektor berbasis jasa yang sangat penting bagi Indonesia. Kekayaan alam merupakan komponen penting dalam dunia pariwisata di Indonesia. Pembangunan sektor pariwisata di Sumatera Barat harus ditingkatkan dan dilanjutkan dengan memperluas dan memanfaatkan sumber budaya serta potensi pariwisata sehingga dapat meningkatkan penerimaan devisa dan pendapatan daerah, serta perluasan lapangan kerja dan kegiatan usaha.

Kedatangan wisatawan juga mempengaruhi tingkat hunian kamar hotel 
dan akomodasi lainnya. Untuk mengambil kebijakan lanjutan dalam pengembangan sektor pariwisata, baik pemerintah maupun pengusaha memerlukan pengolahan data lanjutan dari data Tingkat Penghunian Kamar (TPK) Hotel agar bisa mendapat nilai prediksi kunjungan wisatawan yang berguna dalam mengambil suatu kebijakan untuk kemajuan sektor pariwisata.

Kecerdasaan Buatan (Artificial Intelligence) dalam ilmu komputer banyak digunakan untuk menyelesaikan permasalahan yang berhubungan dengan peramalan atau prediksi, terutama yang berbasis pada data time-series (history). Salah satu cabang Kecerdasan Buatan (AI) yang digunakan untuk peramalan atau prediksi adalah Jaringan Syaraf Tiruan (JST) dengan algoritma Backpropagation. Seperti penerapan model pada Jaringan Syaraf Tiruan yang digunakan untuk memprediksi peningkatan efisiensi peng-gunaan sumber daya pada rumah sakit (Sharikant, 2015), penerapan JST Backpropagation yang digunakan untuk memprediksi prestasi siswa (Lesnussa, Latuconsina, Persulesy, 2015), penerapan Backpropagation yang digunakan untuk prediksi harga indeks saham (Panchal, 2015), penerapan model JST Backpropagation yang digunakan untuk simulasi temperature air laut (Zhao,2015), penerapan Backpropagation yang digunakan untuk pengenalan citra buah manggis (Nursantika, Umbara, 2016).

Prediksi ialah memperkirakan sesuatu yang akan terjadi di masa yang akan datang dengan mempelajari pola data sebelumnya. Hal ini dapat dilakukan dengan melibatkan pengambilan data masa lalu dan menempat-kannya ke masa yang akan datang dengan suatu bentuk model matematis. Bisa juga merupakan prediksi intuisi yang bersifat subjektif. Atau bisa juga dengan menggunakan kombinasi model matematis. Jenis prediksi berdasarkan horizon perencanaan adalah sebagai berikut: (1) Prediksi jangka pendek, Prediksi jangka pendek merupakan waktu prediksi kurang dari tiga bulan; (2) Prediksi jangka menengah; (3) Prediksi jangka menengah merupakan prediksi tiga bulan hingga dua tahun; (4) Prediksi jangka panjang. Prediksi jangka panjang merupa-kan jangka waktu prediksi lebih dari dua tahun.

Jaringan Syaraf Tiruan adalah komputer yang diusahakan agar bisa berpikir sama seperti cara berpikir manusia. Caranya adalah dengan melakukan peniruan terhadap aktivitasaktivitas yang terjadi di dalam sebuah jaringan syaraf biologis. (Puspitaningrum , 2006). Backprogation merupakan suatu teknik pembelajaran atau pelatihan supervised learning yang paling banyak digunakan. Metode ini merupakan salah satu metode yang sangat baik dalam menangani masalah pengenalan pola-pola kompleks. Di dalam Jaringan Syaraf Tiruan Backprogation, setiap unit yang berada dilapisan input terhubung dengan setiap unit yang ada di lapisan tersembunyi. Setiap unit yang ada di lapisan tersembunyi terhubung dengan setiap unit yang ada di lapisan output. Backpropagation melatih jaringan untuk mendapatkan keseimbangan antara kemampuan jaringan untuk mengenali pola yang digunakan selama pelatihan serta kemampuan jaringan untuk memberikan respon yang benar terhadap pola masukan yang serupa (tapi tidak sama) dengan pola yang dipakai selama pelatihan (Siang, 2004).

Jaringan Syaraf Tiruan adalah paradigma pemrosesan suatu informasi yang terinspirasi oleh sistem sel syaraf biologi, sama seperti otak yang memproses suatu informasi. Elemen mendasar dari paradigma tersebut adalah struktur yang baru dari sistim pemrosesan informasi. Jaringan Syaraf Tiruan, seperti manusia, belajar dari suatu contoh. Jaringan Syaraf Tiruan dibentuk untuk memecahkan suatu masalah tertentu seperti pengenalan pola atau klasifikasi karena proses pembelajaran. Kombinasi beberapa neuron sederhana menjadi 
sebuah sistem neural akan meningkatkan kemampuan komputasinya. Bobot dalam jaringan yang diusulkan diatur untuk melakukan fungsi logika sederhana. Fungsi aktivasi yang dipakai adalah fungsi threshold. (McCulloch dan Pits, 1943)

Lapisan-lapisan penyusun Jaringan Syaraf Tiruan tersebut dapat dibagi menjadi tiga bagian:

1. Lapisan input (input layer)

Node-node di dalam lapisan input disebut unit-unit input. Unit-unit input tersebut menerima pola inputan data dari luar yang mengambarkan suatu permasalahan.

2. Lapisan tersembunyi (hidden layer) Node-node di dalam lapisan tersembunyi disebut unit-unit tersembunyi dimana outputnya tidak dapat secara langsung diamati.

3. Lapisan output (output layer)

Node-node di dalam lapisan output disebut unit-unit output. Output dari lapisan ini merupakan solusi Jaringan Syaraf Tiruan terhadap suatu permasalahan.

Langkah 0:

Inisialisasi bobot (ambil bobot awal dengan nilai random yang cukup kecil). Tentukan anggka pembelajaran $(\alpha)$. Tentukan ambang maximal epoch

Langkah 1:

Selama kondisi berhenti belum dicapai, maka lakukan langkah 2 sampai 9.

Langkah 2:

Untuk setiap pasangan pola pelatihan, lakukan langkah ke-3 sampai langkah ke8.

\section{Fase I: Propagasi maju}

Langkah 3:

Tiap-tiap unit input $\mathrm{X}_{\mathrm{i}}$ (dari unit ke-1 sampai unit ke-n pada lapisan input) menerima sinyal $\mathrm{x}_{\mathrm{i}}$ dan meneruskan sinyal tersebut ke semua unit pada lapisan yang ada di atasnya (lapisan tersembunyi).

Langkah 4:

Tiap-tiap unit pada suatu lapisan tersembunyi $Z_{\mathrm{j}}$ (dari unit ke-1 sampai unit ke-p; $\mathrm{i}=1, \ldots, \mathrm{n} ; \mathrm{j}=1, \ldots \mathrm{p})$ sinyal output lapisan tersembunyinya dihitung dengan menerapkan fungsi aktifasi terhdap penjumlahkan sinyal sinyal input berbobot xi :

$$
z_{-}{ }_{i n}=v_{0 j}+\sum_{i=1}^{n} x_{i} v_{i j}
$$

dengan mengggunakan fungsi aktivasi untuk menghitung sinyal output :

$$
\mathrm{z}_{\mathrm{j}}=\mathrm{f}\left(\mathrm{z}_{-} \mathrm{in}_{\mathrm{j}}\right)
$$

dan kirimkan sinyal tersebut ke semua unit di lapisan atasnya (unit-unit output).

Langkah 5 :

Setiap unit dilapisan output $\mathrm{Y}_{\mathrm{k}}$ (dari unit ke-1 sampai unit ke-m; $i=1, \ldots n ; k=1, \ldots, m)$ dihitung sinyal output nya dengan menerapkan fungsi aktivasi terhadap penjumlahan sinyal-sinyal input berbobot zj bagi lapisan ini.

$$
y_{-} i n_{k}=w_{o k}+\sum_{i=1}^{n} z_{i} w_{j k}
$$

Dengan menggunakan fungsi aktivasi untuk menghitung sinyal output :

$$
\mathrm{y}_{\mathrm{k}}=\mathrm{f}\left(\mathrm{y} \_\mathrm{in} \mathrm{k}_{\mathrm{k}}\right)
$$

dan kirimkan sinyal tersebut ke semua unit di lapisan atasnya (unit-unit output).

\section{Fase II : Propagasi mundur}

Langkah 6 :

Tiap-tiap unit output $\left(\mathrm{Y}_{\mathrm{k}}, \mathrm{k}=1,2,3, \ldots, \mathrm{m}\right)$ menerima target pola yang berhubungan dengan pola input pembelajaran, hitung informasi error-nya :

$$
\delta_{k}=\left(t_{k}-y_{k}\right) f^{\prime}\left(y_{-} i_{k}\right)
$$

kemudian hitung koreksi bobot (yang nantinya akan digunakan untuk memperbaiki nilai $\mathrm{w}_{\mathrm{jk}}$ ):

$$
\Delta \mathrm{w}_{\mathrm{jk}}=\alpha \delta_{\mathrm{k}} \mathrm{x}_{\mathrm{j}}
$$

hitung juga koreksi bias (yang nantinya akan digunakan untuk memperbaiki nilai $\left.\Delta \mathrm{w}_{0 \mathrm{k}}\right)$ :

Langkah 7:

$$
\Delta \mathrm{w}_{0 \mathrm{k}}=\alpha \delta_{\mathrm{k}}
$$

Tiap-tiap unit tersembunyi $\left(\mathrm{Z}_{\mathrm{j}}\right.$, $\mathrm{j}=1,2,3, \ldots, \mathrm{p})$ menjumlahkan delta input (dari unit-unit yang berada pada lapisan di atasnya) 


$$
\delta_{-} i n_{j}=\sum_{k=1}^{m} \delta_{k} w_{j k}
$$

kalikan nilai ini dengan turunan dari fungsi aktivasinya untuk menghitung informasi error:

$$
\delta_{\mathrm{j}}=\delta \_\mathrm{in}_{\mathrm{j}} \mathrm{f}^{\prime}\left(\mathrm{z} \_\mathrm{in} \mathrm{n}_{\mathrm{j}}\right)
$$

kemudian hitung koreksi bobot (yang nantinya akan digunakan untuk memperbaiki nilai $\mathrm{v}_{\mathrm{ij}}$ ) :

$$
\Delta \mathrm{v}_{\mathrm{ij}}=\alpha \delta_{\mathrm{i}} \mathrm{x}_{\mathrm{j}}
$$

\section{Fase III : Perubahan bobot}

Langkah 8 :

Tiap-tiap unit output $\left(\mathrm{Y}_{\mathrm{k}}, \mathrm{k}=1,2,3, \ldots, \mathrm{m}\right)$ memperbaiki bias dan bobotnya $(\mathrm{j}=0,1,2, \ldots, \mathrm{p})$ :

$$
\mathrm{w}_{\mathrm{jk}}(\text { baru })=\mathrm{w}_{\mathrm{jk}}(\text { lama })+\Delta \mathrm{w}_{\mathrm{jk}}(2.17)
$$

Tiap-tiap unit tersembunyi $\left(\mathrm{Z}_{\mathrm{j}}\right.$, $\mathrm{j}=1,2,3, \ldots, p)$ memperbaiki bias dan bobotnya $(\mathrm{i}=0,1,2, \ldots, \mathrm{n})$ :

$$
\mathrm{v}_{\mathrm{ij}}(\text { baru })=\mathrm{v}_{\mathrm{ij}}(\text { lama })+\Delta \mathrm{v}_{\mathrm{ij}}(2.18)
$$

Langkah 9: Tes kondisi berhenti.

\section{METODOLOGI}

Metodologi penelitian merupakan urutan dalam melakukan penelitian. Dimaksudkan agar penelitian lebih terkonsep dan terarah sesuai tujuan yang ingin dicapai, sehingga mengahasilkan system yang telah teruji dan dapat memecahkan permasalahan yang diteliti.

Metodologi penelitian digambarkan kedalam bentuk sebuah kerangka kerja. Penelitian dimulai dari mengidentifikasai masalah, menganalisa masalah, menentukan tujuan, studi literatur, mengumpulan data, analisis data dan penentuan pola, pengolahan data dengan algoritma backpropagation, pengolahan data dengan aplikasi MATLAB sampai pada mengevaluasi akhir.

\section{Kerangka Kerja Penelitian}

Bagian ini menggambarkan bagaimana kerangka penelitian yang dilakukan agar senantiasa fokus pada tujuan dan hasil yang diinginkan dengan waktu yang efisien. Adapun kerangka penelitian dapat dilihat pada gambar 1 berikut:

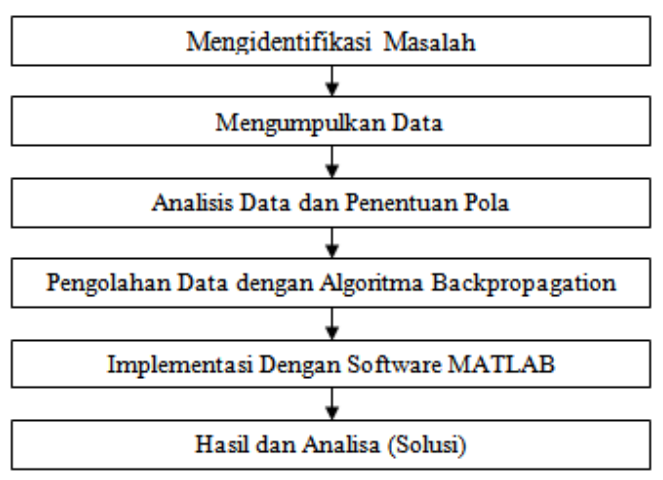

Gambar 1. Kerangka Kerja Penelitian

\section{Analisis Prediksi Kunjungan Wisata- wan \\ Untuk melakukan prediksi tingkat} kunjungan wisatawan, penulis mencoba untuk melakukan pengolahan data yang berpengaruh besar dalam prediksi kunjungan wisatawan. Berikut yang merupakan variabel-variabel yang akan digunakan dalam memprediksi tingkat kunjungan wisatawan:

1. Hotel Bintang 1

2. Hotel Bintang 2

3. Hotel Bintang 3

4. Hotel Bintang 4

5. Akomodasi lainnya (Non Bintang)

Dimana variabel tersebut merupakan variabel input dan variabel target yang digunakan dalam memprediksi kunjungan wisatawan ke Sumatera Barat.

\section{Proses Transformasi Data (Prepro- cessing)}

Dalam proses transformasi, awal tahapannya adalah melakukan pelatihan Jaringan Syaraf Tiruan dengan menggunakan metode backpropagation. Data yang didapat akan diubah dengan proses transformasi sebelum digunakan dalam perhitungan Jaringan Syaraf Tiruan. Transformasi data dilakukan dengan melakukan perubahan terhadap besar skala dari input dan target sehingga 
nantinya proses akan berjalan dengan efisien. Proses transformasi sangat penting dilakukan mengingat Jaringan Syaraf Tiruan tidak dapat mengolah langsung data.

Sebelum ditransformasi, kita akan lakukan pembagian data menjadi data pelatihan dan pengujian. Pembagian data ini dilakukan agar dapat membandingkan hasil pelatihan pada masing-masing bagian. Untuk variabel data yang digunakan dalam proses prediksi dengan Jaringan Syaraf Tiruan ini adalah:

1. X1 : Bintang Satu

2. $\mathrm{X} 2$ : Bintang Dua

3. $\mathrm{X} 3$ : Bintang Tiga

4. X4 : Bintang Empat

5. X5 : Akomodasi Lainnya

Tabel 1. Penyusunan Pola Pelatihan dan Pengujian Data

\begin{tabular}{cccccccc}
\hline Tahun & $\mathbf{X 1}$ & $\mathbf{X 2}$ & $\mathbf{X 3}$ & $\mathbf{X 4}$ & $\mathbf{X 5}$ & $\begin{array}{c}\mathbf{Y} \\
\text { (target) }\end{array}$ \\
\hline $\mathbf{2 0 1 2}$ & 116.11 & 70.35 & 57.45 & 102.40 & 126.13 & 472.45 \\
$\mathbf{2 0 1 3}$ & 155.12 & 86.29 & 88.37 & 162.71 & 118.48 & 610.99 \\
$\mathbf{2 0 1 4}$ & 146.44 & 101.52 & 77.26 & 266.58 & 135.81 & 727.64 \\
$\mathbf{2 0 1 5}$ & 14165 & 112.66 & 119.75 & 293.88 & 145.66 & 813.63 \\
\hline $\mathbf{2 0 1 6}$ & 85.94 & 252.77 & 198.73 & 243.29 & 162.98 & 945.73 \\
\hline $\mathbf{2 0 1 7}$ & 190.18 & 359.01 & 302.97 & 347.53 & 218.79 & 1.418 .51 \\
\hline
\end{tabular}

Fungsi sigmoid adalah fungsi asimtotik (tidak pernah mencapai 0 ataupun 1), maka transformasi data dilakukan pada interval yang lebih kecil yaitu $[0.1 ; 0.8]$, ditunjukkan dengan persamaan.

Keterangan :

$$
X^{t}=\frac{0.8(x-a)}{b-a}+0.1
$$

$0.8=$ Ketetapan

$\mathrm{x}=$ Nilai data ke $-\mathrm{n}$

$\mathrm{a}=$ Nilai data terendah

$\mathrm{b}=$ Nilai data tertinggi

Data pelatihan dan data pengujian yang telah ditransformasi digunakan dalam proses perhitungan algoritma backpropagation.
Tabel 2. Hasil Transformasi pola Penyusunan Pelatihan Data

\begin{tabular}{ccccccc}
\hline Tahun & X1 & X2 & X3 & X4 & X5 & $\begin{array}{c}\text { Y } \\
\text { (target) }\end{array}$ \\
\hline $\mathbf{2 0 1 2}$ & 0.33 & 0.10 & 0.10 & 0.10 & 0.16 & 0.10 \\
$\mathbf{2 0 1 3}$ & 0.63 & 0.14 & 0.20 & 0.30 & 0.10 & 0.22 \\
$\mathbf{2 0 1 4}$ & 0.56 & 0.19 & 0.16 & 0.64 & 0.24 & 0.32 \\
$\mathbf{2 0 1 5}$ & 0.53 & 0.22 & 0.30 & 0.72 & 0.32 & 0.39 \\
$\mathbf{2 0 1 6}$ & 0.10 & 0.61 & 0.56 & 0.56 & 0.45 & 0.50 \\
$\mathbf{2 0 1 7}$ & 0.90 & 0.90 & 0.90 & 0.90 & 0.90 & 0.90 \\
\hline
\end{tabular}

\section{HASIL DAN PEMBAHASAN}

Perancangan Manual Jaringan Syaraf Tiruan

a. Berikan nilai bobot $(V)$ dari input ke lapisan tersembunyi (hidden layer).

Tabel 3. Nilai Bobot Input ke Hidden Layer Pola 5-5-1

\begin{tabular}{cccccc}
\hline Bobot & $\mathbf{Z 1}$ & $\mathbf{Z 2}$ & $\mathbf{Z 3}$ & $\mathbf{Z 4}$ & $\mathbf{Z 5}$ \\
\hline V1 & 3,4098 & 4,7837 & $-6,6371$ & 2,8943 & 2,5178 \\
V2 & $-1,8693$ & 0,8564 & 6,1720 & $-2,4210$ & $-6,7154$ \\
V3 & 7,2674 & $-5,0044$ & $-2,0283$ & $-3,2883$ & 0,7014 \\
V4 & 0,5481 & 2,7744 & 5,3477 & $-5,0020$ & $-5,6270$ \\
V5 & $-1,5587$ & 6,4783 & 0,0539 & $-5,8738$ & 3,7917 \\
\hline
\end{tabular}

b. Berikan nilai bobot dari lapisan tersembunyi ke output.

Tabel 4. Nilai Bobot Dari Hidden Layer ke Output Pola 5-5-1

\begin{tabular}{cc}
\hline Bobot & $\mathbf{Y}$ \\
\hline W1 & $-0,2433$ \\
W2 & 0,7200 \\
W3 & 0,7073 \\
W4 & 0,1871 \\
W5 & $-0,0069$ \\
\hline
\end{tabular}

c. Berikan nilai bias $\left(V_{j o}\right)$ dari input ke lapisan tersembunyi (hidden layer),

Tabel 5. Nilai Bias Dari Input Ke Hidden Layer Pola 5-5-1

\begin{tabular}{cccccc}
\hline Bias & $\mathbf{1}$ & $\mathbf{2}$ & $\mathbf{3}$ & $\mathbf{4}$ & $\mathbf{5}$ \\
\hline $\mathbf{V j}$ & $-7,3475$ & 3,9203 & 1,1761 & $-0,4041$ & $-5,3090$ \\
\hline
\end{tabular}


d. Berikan nilai bias $\left(W_{j o}\right)$ dari lapisan tersembunyi ke output,

Tabel 6. Nilai Bias Hidden ke Output $5-5-1$

\begin{tabular}{cc}
\hline Bias & $\mathbf{1}$ \\
\hline $\mathbf{W j}$ & 0,7995 \\
\hline
\end{tabular}

Tahap Iterasi :

a. Menentukan input pada neuron hidden Untuk mendapatkan nilai input pada masing-masing neuron hidden maka akan dilakukan langkah perhitungan dengan cara mengalikan masingmasing nilai pada neuron input dengan masing-masing bobotnya.

b. Menentukan output neuron pada neuron hidden

Setelah perhitungan input dari masingmasing neuron hidden, maka langkah berikutnya dilanjutkan dengan menghitung nilai keluaran dari masing-masing neuron hidden dengan memasukan fungsi aktivasi, fungsi aktivasi yang digunakan yaitu Sigmoid Biner.

c. Menetukan output pada neuron output Selanjutnya menghitung input dari neuron output, yaitu dengan mengalikan nilai keluaran dari lapisan tersembunyi dengan masing-masing neuron hidden kelapisan output.

d. Menentukan Faktor $\delta$ di unit keluran $Y_{-}((k))$ (Tahapan Perambatan Balik).

Hitung suku perubahan bobot $W_{-} o j$ (digunakan dalam merubah bobot $W_{-} o j$ dengan laju pembelajaran (learning rate) $\alpha=0,5$.

e. Menentukan jumlah kesalahan dari unit tersembunyi (hidden)

Kemudian hitung factor kesalahan $\delta$ di unit tersembunyi (hidden)

Hitung suku perubahan bobot ke unit tersembunyi

Langkah setelah ini adalah menghitung nilai bobot unit tersembunyi (hidden)

Langkah berikutnya hitung peru- bahan nilai bobot garis yang menuju ke unit keluaran (output).

Langkah selanjutnya hitung koreksi nilai Bias dari unit tersembunyi (hidden).

Lanjutkan dengan mencari nilai bias baru pada unit keluaran (hidden) dengan persamaan.

Hitung perubahan nilai bias dari unit tersembunyi ke output.

Setelah proses pelatihan selesai, data keluaran yang sudah didapatkan dari pelatihan jaringan adalah yang masih dalam bentuk normalisasi, sehingga harus dilakukannya proses denormalisasi data yang bertujuan untuk mengembalikan nilai hasil keluaran data yang masih dalam bentuk normalisasi kedalam bentuk data yang sebenarnya. Hasil ini masih jauh dari target yang dinginkan, jadi pelatihan dan pengujian yang dilakukan tidak cukup hanya dengan satu jenis arsitektur jaringan saja, tapi harus dibandingkan dengan arsitektur jaringan lain, dan tidak cukup hanya pada tahap iterasi tahap I saja, harus dilakukan sebanyak mungkin sampai menemukan hasil dibawah nilai nol atau tingkat error yang terendah sebanyak-banyaknya. Maka untuk melakukan pengolahan yang lebih banyak tidak mungkin dilakukan secara manual, tapi harus menggunakan alat bantu, dalam hal ini penulis menggunakan Software Matlab.

\section{Pelatihan dan Pengujian dengan MATLAB}

Dalam melakukan pelatihan dan pengujian hasil dari prediksi kunjungan wisatawan ke Sumatera Barat, maka pengenalan pola tersebut juga akan diujikan ke dalam sistem terkomputerisasi. Pelatihan yang dilakukan dalam Matlab dapat menggunakan berbagai fungsi, tujuannya adalah untuk mempercepat pelatihan.

Langkah pertama yang harus dilakukan untuk metode Backpropagation dengan Matlab adalah dengan membuat inisialisasi jaringan. Matlab (Matrix 
Available online at http://jurnal.stmikroyal.ac.id/index.php/jurteksi

Tabel 7. Perbandingan Epoch dan MSE dari Pola Yang Diuji

\begin{tabular}{cccccc}
\hline & $\mathbf{5 - 5 - 1}$ & $\mathbf{5 - 4 - 1}$ & $\mathbf{5 - 3 - 1}$ & $\mathbf{5 - 2 - 1}$ & $\mathbf{5 - 1 - 1}$ \\
\hline $\begin{array}{c}\text { Epoch } \\
\text { Pelatihan }\end{array}$ & 389 & 1850 & 26463 & 5410 & 2781 \\
$\begin{array}{c}\text { MSE } \\
\text { Pengujian }\end{array}$ & 0,000996 & 0,000999 & 0,00100 & 0,0010 & 0,000998 \\
$\begin{array}{c}\text { Akurasi } \\
(\mathbf{1 0 0 - M S E )}\end{array}$ & 99,999004 & 99,999001 & 99,9990 & 99,9990 & 99,999002 \\
\hline
\end{tabular}

Tabel 8. Perbandingan Hasil Prediksi

\begin{tabular}{ccccc}
\hline \multirow{2}{*}{ Tahun } & \multirow{2}{*}{ Aktual } & $\begin{array}{c}\text { Prediksi } \\
\text { JST }\end{array}$ & Selisih & \%Error \\
\hline $\mathbf{2 0 1 2}$ & $472,452.00$ & $482,331.92$ & $9,879.92$ & 2.09 \\
$\mathbf{2 0 1 3}$ & $610,991.00$ & $623,249.31$ & $12,258.31$ & 2.01 \\
$\mathbf{2 0 1 4}$ & 727,640 & 739,340 & $11,700.45$ & 1.61 \\
$\mathbf{2 0 1 5}$ & $813,630.00$ & 825,730 & $12,100.31$ & 1.49 \\
$\mathbf{2 0 1 6}$ & $945,735.00$ & $955,747.50$ & 101.0587 & 1.06 \\
$\mathbf{2 0 1 7}$ & $1,418,511.00$ & $1,425,258.86$ & $6,747.86$ & 0.48 \\
Jumlah & $4,988,959.00$ & $5,051,658.34$ & $62,699.34$ & 8.73 \\
Rata-Rata & $831,493.17$ & $841,943.06$ & $10,449.89$ & 1.45 \\
\hline
\end{tabular}

Laboratory) merupakan salah satu perangkat lunak yang cocok dipakai sebagai alat komputasi yang melibatkan matriks dan vector.

\section{SIMPULAN}

Berdasarkan analisa data dan pengujian di atas, dapat diambil beberapa kesimpulan sebagai berikut:

1. Dari data di atas dapat dilihat tingkat persentase error terkecil adalah 0.48 dengan jumlah prediksi 1,425,258.86 yang dapat dijadikan gambaran untuk tingkat kunjungan wisatawan berdasarkan tingkat hunian hotel di tahun berikutnya.

\section{DAFTAR PUSTAKA}

Badan Pusat Statistik Provinsi Sumatera Barat (2016). "Tingkat Penghunian Kamar Hotel Sumatera Barat".
2. Dengan menerapkan metode Backpropagation, kita dapat memprediksi kunjungan wisatawan dari data yang tersedia.

3. Untuk pengembangan selanjutnya, dapat menggunakan parameter pelatihan yang berbeda, misalnya dengan menggunakan momentum serta jumlah lapisan tersembunyi yang lebih banyak. Jumlah data latih yang digunakan sebaiknya juga diperbanyak (jika memungkinkan) agar prediksi yang dihasilkan semakin akurat. 
For Measuring The Severity of Osteoarthritis", Vol.11 (3)

Dian N. and Fajri Rahmat U., (2016). "Pengenalan Citra Buah Manggis Menggunakan Metode Jaringan Syaraf Tiruan Backpropagation”. Mei 2016.

Kadu Parag P., (2013). "Temperature Prediction System Using Backpropagation Neural Network : An Approch", ,Vol. 2 : 61-64

Lesnussa Y.A., Latuconsina S., and Persulessy E.R., (2015). “Aplikasi Jaringan Syaraf Tiruan Backpropagation Untuk Memprediksi Prestasi Siswa SMA (Studi Kasus: SMAN 4 Ambon)". Jurnal Matematika Integratif. Volume 11 (2), Oktober 2015,

Oktaviani U., Beni I., and Fatma A.S., (2014)."Diagnosa Gizi Pada Anak Balita Dengan Menggunakan Metode Jaringan Syaraf Tiruan Metode Backpropagation".Vol. 02 (1) 2014.

Panchal Amit M., (2015). “National Stock Exchange Stock And Index Price Direction Prediction Using Backpropagation Artificial
Neural Network" , International Journal of Innovative Research in Science, Engineering and Technology. Vol. 4 (11), November 2015.

Puspitaningrum D., (2004). "Pengantar Jaringan Syaraf Tiruan". Jakarta : Penerbit Andi.

Siang J.J., (2004). "Jaringan Syaraf Tiruan dan Pemogramannya Dengan Matlab". Jakarta: Andi.

Srikanth K., (2015). "Prediction Model to Enchane Resource Efficiently For Hospitals". Vol. 4 (9), September 2015.

Risnawati, R., \& Handayani, M. (2017). penerapan Jaringan Saraf Tiruan Untuk Proyeksi Logistik Berdasarkan Prediksi Pasien Menggunakan Algoritma Backpropagation. JURTEKSI, 4(1 ), 21-28.

Syah, A. Z., Siagian, Y., \& Aswati, S. (2017). PENCIRIAN WICARA MENGGUNAKAN ANALISA CEPTRAL SEBAGAI WUJUD INVERS DARI FAST FORIER TRANSFORM (FFT). JURTEKSI ROYAL Vol 3 No 2, 3. 